\title{
Mussel-inspired co-deposition to enhance bisphenol A removal in a bifacial enzymatic
} membrane reactor

\author{
Cao, Xiaotong; Luo, Jianquan; Woodley, John M.; Wan, Yinhua
}

Published in:

Chemical Engineering Journal

Link to article, DOI:

10.1016/j.cej.2017.12.042

Publication date:

2018

Document Version

Peer reviewed version

Link back to DTU Orbit

Citation (APA):

Cao, X., Luo, J., Woodley, J. M., \& Wan, Y. (2018). Mussel-inspired co-deposition to enhance bisphenol A removal in a bifacial enzymatic membrane reactor. Chemical Engineering Journal, 336, 315-324. https://doi.org/10.1016/j.cej.2017.12.042

\section{General rights}

Copyright and moral rights for the publications made accessible in the public portal are retained by the authors and/or other copyright owners and it is a condition of accessing publications that users recognise and abide by the legal requirements associated with these rights.

- Users may download and print one copy of any publication from the public portal for the purpose of private study or research.

- You may not further distribute the material or use it for any profit-making activity or commercial gain

- You may freely distribute the URL identifying the publication in the public portal 


\section{Accepted Manuscript}

Mussel-inspired co-deposition to enhance bisphenol A removal in a bifacial enzymatic membrane reactor

Xiaotong Cao, Jianquan Luo, John M. Woodley, Yinhua Wan

PII:

$$
\text { S1385-8947(17)32155-1 }
$$

DOI: https://doi.org/10.1016/j.cej.2017.12.042

Reference: CEJ 18203

To appear in:

$$
\text { Chemical Engineering Journal }
$$

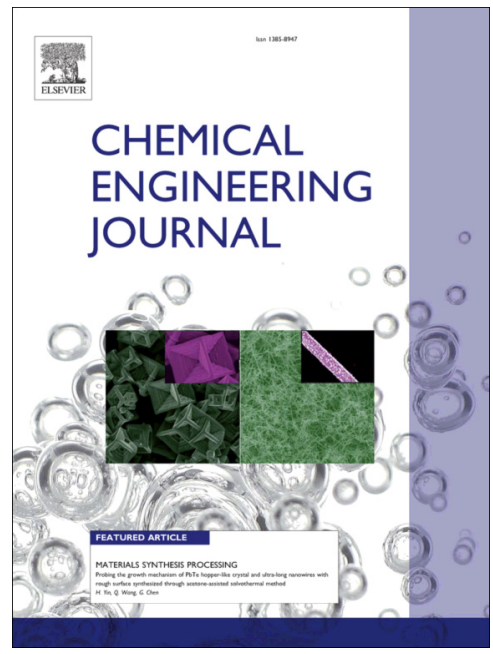

Received Date: $\quad 14$ October 2017

Revised Date: 7 December 2017

Accepted Date: $\quad 9$ December 2017

Please cite this article as: X. Cao, J. Luo, J.M. Woodley, Y. Wan, Mussel-inspired co-deposition to enhance bisphenol A removal in a bifacial enzymatic membrane reactor, Chemical Engineering Journal (2017), doi: https://doi.org/ 10.1016/j.cej.2017.12.042

This is a PDF file of an unedited manuscript that has been accepted for publication. As a service to our customers we are providing this early version of the manuscript. The manuscript will undergo copyediting, typesetting, and review of the resulting proof before it is published in its final form. Please note that during the production process errors may be discovered which could affect the content, and all legal disclaimers that apply to the journal pertain. 


\section{Mussel-inspired co-deposition to enhance bisphenol A removal in a bifacial enzymatic membrane reactor}

Xiaotong Cao, ${ }^{\mathrm{a}, \mathrm{b}}$ Jianquan Luo, ${ }^{\mathrm{a}, \mathrm{b}^{*}} \mathrm{John}_{\mathrm{M}}$. Woodley ${ }^{\mathrm{c}}$ and Yinhua Wan ${ }^{\mathrm{a}, \mathrm{b}^{*}}$

${ }^{a}$ State Key Laboratory of Biochemical Engineering, Institute of Process Engineering, Chinese Academy of Sciences, Beijing 100190, PR China

${ }^{b}$ University of Chinese Academy of Sciences, Beijing 100049, PR China

${ }^{c}$ Department of Chemical and Biochemical Engineering, Technical University of Denmark, 2800, Kgs. Lyngby, Denmark

*Corresponding authors: E-mail: jqluo@ipe.ac.cn (J. Luo); yhwan@ipe.ac.cn (Y. Wan) Tel/Fax: $+86-10-62650673$ 


\section{Abstract}

In this study, the biocatalytic membranes were prepared by 'reverse filtration' of laccase and subsequently various mussel-inspired coating strategies: single dopamine (DA) deposition, DA/polyethyleneimine (PEI) co-deposition, and DA/ $\mathrm{Cu}^{2+}$ co-deposition, where nanofiltration (NF) membranes were used as the matrix to further exploit the potential of the biocatalytic membranes. such prepared biocatalytic membranes were enzymatically active on both sides, making it possible to construct a bifacial enzymatic membrane reactor (EMR) for highly efficient micro-pollutants removal (taking bisphenol A (BPA) as an example). Compared with the single polydopamine (PDA) coated membrane, the biocatalytic membranes prepared by DA/PEI and DA/ $\mathrm{Cu}^{2+}$ co-depositions exhibited much better performances in terms of enzyme loading, activity and permeability as well as the stability of immobilized enzyme. The BPA removal efficiency was highest for the EMR with the PDA/Cu ${ }^{2+}$ coated membrane attributed to copper-enhanced electron transfer, while it was lowest for the EMR with the PDA/PEI coated membrane due to the high diffusional resistance of the dense PDA/PEI layer. Meanwhile, the mechanism for performance deterioration of biocatalytic membrane during BPA treatment was revealed, and it was found that the trade-off between BPA removal efficiency and long-term stability could be broken by applying the bifacial EMR with PDA/Cu${ }^{2+}$ coated membrane in flow-through mode, since the pressure-induced convective mass transfer improved the substrate accessibility to enzyme together with products removal.

Keywords: laccase immobilization; biocatalytic membrane; micro-pollutant; tertiary wastewater treatment; enzymatic membrane reactor 


\section{Introduction}

Many micro-pollutants such as antibiotics, pharmaceuticals, endocrine disruptors, pesticides and personal care products are found in aquatic resources [1-4], displaying a long-term adverse impact on the ecosystem and human [5]. For example, Bisphenol A (BPA), a widely used additive in polycarbonate plastics and epoxy resins, could enter human body via diet, inhalation and dermal absorption easily, bringing adverse effects on reproduction and development systems, neural networks, and cardiovascular, metabolic, and immune systems [6].

Various methods have been used to remove micro-pollutants, such as membrane filtration [7], adsorption [8], biodegradation [9], chemical/ electrochemical/ photo oxidations [10, 11], and membrane bioreactor $[11,12]$, among which the enzymatic membrane reactors (EMRs) are most attractive $[13,14]$ due to their high efficiency, no or less harm to environment etc. For the enzymes used in EMRs, ligninolytic enzymes such as laccase (E.C. 1.10.3.2) are under extensive research because they can effectively oxidize a wide range of pollutants to environmental-friendly products [15], and significant progresses in micro-pollutants removal by laccase-loaded EMR have been made $[4,5,13,14]$. Nevertheless, the commonly used micro-filtration (MF) or ultra-filtration (UF) membranes in EMRs could not really retain the small micro-pollutants, and the enzymatic reaction efficiency was limited due to the short residence time under flow-through mode. On the other hand, although the enzyme loading and activity retention were greatly imporved by entraping enzymes in membrane, a huge permeability loss and enzyme leakage were inevitable during the application [16]. To overcome the aforementioned drawbacks, we have previously immobilized laccase by 'reverse filtration' of laccase solution followed by 'dopamine (DA) coating' in/on the nanofiltration (NF) membrane support $[17,18]$. Using this novel method, the trade-off between permeability and 
enzyme loading was broken, and such a membrane improved enzymatic efficiency for BPA removal due to the synergistic effect between retention, adsorption and catalysis [18]. However, due to the porous structure of polydopamine (PDA) layer (for 'sealing' enzyme), enzyme leakage could not be completely overcome, and the performance decline of EMR was obvious during long-term operation [18]. Thus, it is of great significance to solve this problem and improve the overall performance of the EMR.

PDA, a thin and adhesive film inspired by the Mytilus edulis foot, is produced by DA self-polymerization under alkaline condition with oxygen, and it has been widely used in surface modification [19-22]. It was found that the addition of low molecular-weight polyethyleneimine (PEI, $600 \mathrm{Da}$ ) could promote the homogeneous polymerization and deposition of DA [23], and even a NF membrane could be prepared by the co-deposition of DA/PEI on a UF membrane followed by crosslinking, which exhibited a high rejection for multivalent cations [24]. Inspired by this, we reasoned that DA/PEI co-deposition might form a much denser and more hydrophilic network to better 'seal' the enzymes in the membrane support. On the other hand, the addition of copper ions could also accelerate DA polymerization even at acidic $\mathrm{pH}$ [25-27]. Additionally, it has been found that the nano-coppers could facilitate the electron transfer in the catalytic reaction of 2,4,6-Trichlorophenol by laccase [28], hence we hypothesize DA/ $\mathrm{Cu}^{2+}$ co-deposition may benefit laccase activity and micro-pollutants removal. Although the co-deposition of DA/PEI or DA/Cu${ }^{2+}$ has been widely used for membrane fabrication and modification, there has been no report regarding its application in enzyme immobilization. In addition, since the enzyme is located between the skin and the support layers for the biocatalytic membrane prepared by 'reverse filtration' followed by 'DA coating', the enzymatic reaction might take place on both sides of the 
membrane in the EMR (the substrate could contact with enzyme by pressure-driven convective transport or by concentration gradient-driven diffusion from both sides), which can be termed as 'bifacial EMR'. In fact the thickness of the polyamide skin layer is only tens to hundreds of nanometers, and monovalent ions can easily pass through this thin layer, enabling electron transfer across this layer. Furthermore, laccase oxidation in EMR could be enhanced by co-depositions as PDA, PEI and copper are all beneficial to electron transfer [28-30]. The aforementioned advantages of this bifacial EMR might therefore allow it to outperform the conventional EMR where the enzyme is immobilized on the skin layer and the reaction takes place only on one side.

In this work we hence prepared three kinds of biocatalytic membranes via 'reverse filtration' of laccase solution followed by different mussel-inspired coating strategies: single DA deposition, DA/PEI co-deposition, and DA/Cu ${ }^{2+}$ co-deposition as illustrated in Fig. 1. We have investigated in detail the surface structure, enzyme loading, activity and enzyme leakage of the biocatalytic membranes as well as BPA removal performance (i.e. efficiency and stability) in the EMRs. Besides, the mechanisms involved in EMR's efficiency decline during long-term operation were also revealed. To the best of our knowledge, this is the first work employing DA/PEI and DA/Cu${ }^{2+}$ co-depositions to construct bifacial EMRs for highly efficient micro-pollutants removal. The successful implementation of this work will open new direction for biocatalytic membrane preparation, and provide practical strategies to improve EMR's performance by applying different EMRs (bifacial EMR and conventional single-side EMR) and operation modes (contact mode and flow-through mode). 

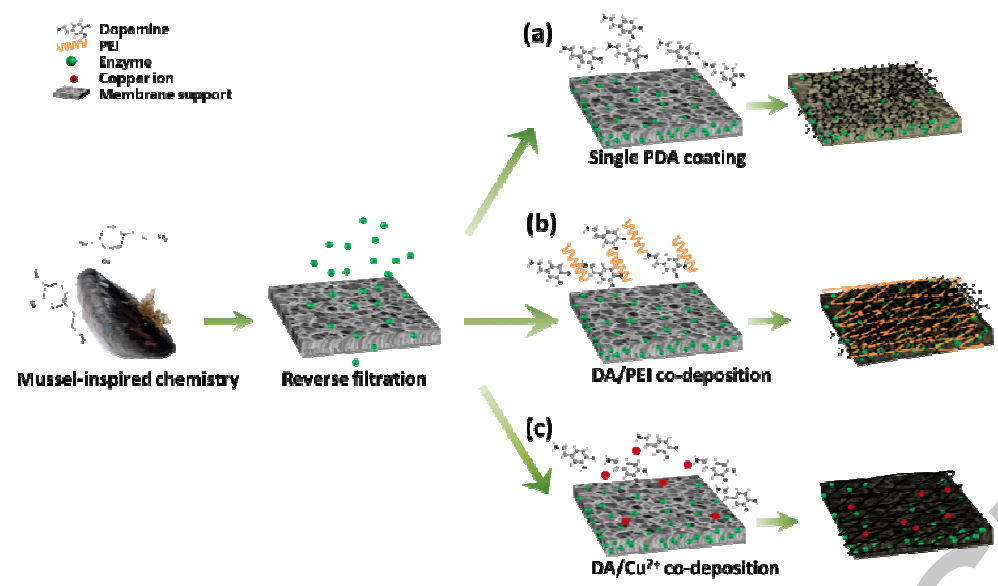

Fig. 1 Schematic diagram of biocatalytic membrane preparation via mussel-inspired coatings. Enzyme immobilization was carried out by 'reverse filtration' of laccase and subsequent PDA coating on the support layer via (a) single DA self-polymerization, (b) DA/PEI co-deposition (c) DA/Cu ${ }^{2+}$ co-deposition under alkaline condition.

\section{Material and methods}

\subsection{Materials}

NF270 membrane (semi-aromatic polyamide, molecular weight cut-off: 200-300 Da) was purchased from Dow-Filmtec Co. (USA). Bradford reagent used for the protein assay, laccase (EC 1.10.3.2, 60-70 $\mathrm{KDa}, 0.53 \mathrm{U} \cdot \mathrm{mg}^{-1}$ ) from Trametes versicolor, dopamine hydrochloride, and polyethyleneimine (PEI, Mw=600 Da, $750000 \mathrm{Da})$ were purchased from Sigma-Aldrich Co. (China). 2.6-dimethoxy phenol (DMP, $154.16 \mathrm{~g} \cdot \mathrm{mol}^{-1}$ ) used as the activity assay substrate, BPA $\left(228.29 \mathrm{~g} \cdot \mathrm{mol}^{-1}\right)$ and copper (II) sulfate pentahydrate $\left(\mathrm{CuSO}_{4} \cdot 5 \mathrm{H}_{2} \mathrm{O}\right)$ were supplied by Aladdin Co. (China). All the laccase solutions and BPA solutions were prepared using $10 \mathrm{mM}$ acetate buffer (pH 5.0). Dopamine hydrochloride solution $\left(2 \mathrm{~g} \cdot \mathrm{L}^{-1}\right)$ was prepared freshly using $10 \mathrm{mM}$ Tris-HCl buffer ( $\mathrm{pH}$ 8.5) and DMP solution (10 mM) was prepared using $100 \mathrm{mM}$ sodium citrate buffer ( $\mathrm{pH} 4.3)$. All of the chemical reagents used in this work were of analytical grade and used without any further purification. 


\subsection{Preparation of biocatalytic membrane}

\subsubsection{Enzyme immobilization}

The preparation of the biocatalytic membranes was performed via 'reverse filtration' of laccase solution followed by dopamine-based deposition in a dead-end filtration cell (Amicon 8050, Millipore Co., USA) with an effective membrane surface area of $13.4 \mathrm{~cm}^{2}$. In detail, the membrane was placed in a filtration cell under 'sandwich' mode (support layer facing the feed solution with an extra polypropylene support beneath the skin layer to avoid the delamination of the skin layer from the supporting layer) and washed using deionized water for $30 \mathrm{~min}$, then $20 \mathrm{~mL}$ of enzyme solution ( $1 \mathrm{~g} \cdot \mathrm{L}^{-1}$, close to optimal enzyme dosage determined by previous work [18]) was added into the filtration cell for enzyme immobilization (i.e. reverse filtration at 4 bar with agitation speed of 100 $\mathrm{rpm})$. After $18 \mathrm{~mL}$ of permeate passed through the membrane, filtration was stopped and the enzyme-loaded membrane was washed using $10 \mathrm{~mL}$ deionized water under 2 bar. The retentate and washing residual $(12 \mathrm{~mL})$ were collected together for further analysis. After enzyme immobilization, three different coating protocols were conducted respectively, as shown in Fig. 1. For single DA coating, $10 \mathrm{~mL}$ of dopamine hydrochloride solution was poured into the open filtration cell with an enzyme-loaded membrane and the coating was carried out at room temperature with agitation speed of $100 \mathrm{rpm}$ for $1 \mathrm{~h}$. For DA/PEI co-deposition, $10 \mathrm{~mL}$ Tris- $\mathrm{HCl}$ buffer containing dopamine hydrochloride $\left(2 \mathrm{~g} \cdot \mathrm{L}^{-1}\right)$ and PEI $\left(\mathrm{Mw}=600 \mathrm{Da}, 2 \mathrm{~g} \cdot \mathrm{L}^{-1}\right)$ was added into the filtration cell for co-deposition under the same condition as single DA coating. While for DA/Cu ${ }^{2+}$ co-deposition, the coating solution was prepared by dissolving $3 \mathrm{mM} \mathrm{CuSO} \cdot 5 \mathrm{H}_{2} \mathrm{O}$ in $10 \mathrm{~mL}$ of Tris- $\mathrm{HCl}$ buffer, followed by dissolution of $0.02 \mathrm{~g}$ dopamine hydrochloride. After coating, membranes were cleaned using deionized water at 2 bar to wash the unbound molecules. Finally, the biocatalytic membranes 
were stored in $10 \mathrm{~mL}$ phosphate buffer $(\mathrm{pH} 7)$ at $4{ }^{\circ} \mathrm{C}$ overnight and washed using $10 \mathrm{~mL}$ deionized water at 2 bar in normal mode next day. The buffer used for soaking and the water used for washing (20 $\mathrm{mL}$ in total) were collected and analysed to measure enzyme leakage. During this process, the membrane permeability at different enzyme immobilization stages was measured. Further details have been reported in our previous work $[17,18]$.

\subsubsection{Enzyme loading and activity assay}

The enzyme concentration for all enzyme solutions at different immobilization stages was measured as a protein concentration using the Bradford assay with a spectrophotometer (UV-2100, UNIC Co., China) and enzyme loading was calculated according to the mass balance equation:

$$
m_{\text {immobilized }}=m_{\text {total }}-C_{p} \cdot V_{p}-C_{r w} \cdot V_{r w}-C_{s w} \cdot V_{s w}
$$

Enzyme loading efficiency was calculated as:

$$
\text { Enzyme loading efficiency }=\frac{m_{\text {immobilized }}}{m_{\text {total }}} \times 100 \%
$$

where $m_{\text {total }}$ and $m_{\text {immobilized }}$ were the enzyme amount in the feed solution and the immobilized enzyme amount, respectively; $C_{p}, C_{r w}$ and $C_{S w}$ were the enzyme concentrations in the permeate $(18 \mathrm{~mL})$, in the mixture of retentate and washing residuals $(12 \mathrm{~mL}$, before coating), and in the mixture of soaking and washing residuals $\left(20 \mathrm{~mL}\right.$, after membrane reversal), respectively; $V_{p}, V_{r w}$ and $V_{s w}$ were the enzyme solution volumes of the permeate, the mixture of retentate and washing residuals, the mixture of soaking and washing residues respectively.

Activity assay was performed by monitoring the oxidation rate of DMP (10 mM, pH 4.3). First, the biocatalytic membrane with an effective surface area of $13.4 \mathrm{~cm}^{2}$ was placed in the filtration cell under normal mode (only skin layer facing DMP solution) and then $10 \mathrm{~mL}$ DMP solution was poured into the open cell with $100 \mathrm{rpm}$ agitation. The absorbance changes at $468 \mathrm{~nm}$ was recorded 
using a spectrophotometer (UV-2100, UNIC Co., China) every 30 seconds. After that, the membrane was cleaned using neutral phosphate buffer until no absorbance at $468 \mathrm{~nm}$ in the cleaning buffer was detected. Afterwards, it was placed in reverse mode (only support layer facing DMP solution) and the oxidation rate of DMP by support layer was measured as described above. The activity of immobilized laccase of both sides of the biocatalytic membranes was calculated from the molar absorptivity, $\varepsilon_{468 \mathrm{~nm}}=49.6 \cdot(\mathrm{mM} \cdot \mathrm{cm})^{-1}$ and was expressed in " $\mathrm{nmol}_{\mathrm{DMP}} \cdot \mathrm{min}^{-1}$. The glass cuvette used had an effective length of $1 \mathrm{~cm}$.

\subsubsection{Stability of immobilized enzyme}

Stability of immobilized enzyme was investigated by measuring the enzyme leakage for the different biocatalytic membranes, where three kinds of biocatalytic membranes (prepared by $45 \mathrm{~mL}$ of laccase solution with a concentration of $1 \mathrm{~g} \cdot \mathrm{L}^{-1}$ ) were stored in neutral phosphate buffer at $4{ }^{\circ} \mathrm{C}$ for 9 days and the amount of free enzyme in storage buffer was measured every day.

\subsection{Characterization of biocatalytic membranes}

The cross-sectional morphologies of the sublayer for three biocatalytic membranes were observed using Scanning Electron Microscope (JSM 6700F, JEOL Co., Japan) under 5 KV operational voltages and $10 \mu \mathrm{A}$ operational current. The water contact angle measurements were performed using a contact angle system (OCA20, Data Physics Co., Germany) with the sessile drop method at room temperature to determine membrane hydrophilicity. The chemical groups of the biocatalytic membrane surface were investigated by Fourier Transform Infrared (FT-IR) spectra via an FT-IR spectrometer (Nicolet iS50, Thermo Fisher Co., USA). X-Ray photoelectron spectroscopy (XPS, Thermoescalab 250Xi, Thermo Fisher Scientific Co., USA) elemental analysis with monochromatic Al-Ka X-ray source $(\mathrm{hv}=1486.6 \mathrm{eV})$ was used to detect the elemental composition 
of the membrane surface in detail. The surface element distribution of the membranes was also examined using Energy Dispersive X-Ray Spectroscopy (EDX, SU8020 Scanning Electron Microscope, Hitachi Co., Japan).

\subsection{BPA removal in bifacial EMRs}

\subsubsection{Contribution of each side of biocatalytic membrane to BPA removal}

The procedure of BPA removal measurement for each membrane side was similar to enzyme activity assay (Section 2.2.2), where the membrane was placed in the filtration cell under normal mode firstly (only skin layer facing BPA) and then $10 \mathrm{~mL}$ BPA solution $\left(5 \mathrm{mg} \cdot \mathrm{L}^{-1}\right)$ was poured into the open cell to react (room temperature, $100 \mathrm{rpm}, 1 \mathrm{~h}$ ). The BPA concentrations before and after reaction were measured to determine BPA removal by mass balance. Afterwards, the membrane was cleaned and placed in filtration cell under 'reverse' mode (support layer facing BPA) subsequently to measure BPA removal by the membrane support using the identical procedures described above.

\subsubsection{BPA removal in bifacial EMRs under contact mode}

The biocatalytic membranes were used to treat BPA solution with different concentrations $(2,5$ and $10 \mathrm{mg} \cdot \mathrm{L}^{-1}$ ) in contact mode for 9 reuse cycles (each cycle took $6 \mathrm{~h}$ ). In detail, the biocatalytic membranes were immersed entirely in $20 \mathrm{~mL}$ of BPA solution at room temperature with agitation speed of $100 \mathrm{rpm}$ for $6 \mathrm{~h}$, and BPA concentrations before and after treatment were measured. At the end of each cycle, the biocatalytic membranes were washed using acetate buffer ( $\mathrm{pH} 5.0$ ) until no further BPA molecules were detected in the washing solution.

\subsubsection{BPA removal in bifacial EMRs under flow-through mode}

The bifacial EMRs prepared by DA/Cu${ }^{2+}$ co-deposition were used to treat BPA solution $(20 \mathrm{~mL}$, $\left.2 \mathrm{mg} \cdot \mathrm{L}^{-1}\right)$ under flow-through mode, where the permeate was re-circulated to the filtration cell and 
the TMP was controlled manually to keep constant permeate flux $\left(6.72 \mathrm{~L} \cdot \mathrm{m}^{-2} \cdot \mathrm{h}^{-1}\right)$ for $6 \mathrm{~h}$. Finally, the permeate and the retentate were combined together and the BPA concentration of the final solution was measured. Prior to next cycle, the used membrane was washed using acetate buffer to remove residual BPA molecules. The EMR was reused for 9 cycles and the corresponding BPA removal was recorded.

Quantitative analysis of BPA was performed using High Performance Liquid Chromatography (HPLC, Shimadzu Co., Japan) with a C18 HPLC column (ZORBAX SB-C18, $250 \mathrm{~mm} \times 4.6 \mathrm{~mm}$ i.d.; $5 \mu \mathrm{m}$; Agilent Co., USA). The enzymatic reaction was terminated by mixing the treated solution with $0.1 \mathrm{M} \mathrm{HCl}$. The detailed HPLC analytical conditions were set as follows: isocratic elution with 50\% HPLC-grade water and $50 \%$ acetonitrile $(\mathrm{V} / \mathrm{V})$ with a flow rate of $1.0 \mathrm{~mL} \cdot \mathrm{min}^{-1}$; the column oven temperature of $40{ }^{\circ} \mathrm{C}$; the detection at $278 \mathrm{~nm}$ and injection volume of $50 \mu \mathrm{L}$. The BPA retention time was $5.85 \pm 0.070$ min. BPA removal was measured as the reduction ratio of BPA concentrations before and after treatments (under both operation modes, BPA concentration variation could represent mass variation because the volume of BPA solution was unchanged), which was calculated according to the following equation:

$$
X_{B P A}=\left(1-\frac{C_{\text {after treatment }}}{C_{\text {feed }}}\right) \times 100 \%
$$

where $C_{\text {feed }}$ and $C_{\text {after treatment }}$ represented the BPA concentrations before and after treatment, respectively.

\section{Results and discussion}

\subsection{Preparation of biocatalytic membrane}

\subsubsection{Characterization of biocatalytic membranes}


As seen in Fig. 2A, compared to the membrane with single PDA coating, the support layer of the PDA/PEI coated membrane has more uniform colour while its skin layer seems much cleaner. This could be explained by the fact that the incorporation of PEI inhibited PDA aggregate formation via Schiff base or Michael addition reaction between PEI and PDA [31], and the PEI-PDA polymers could only deposit in the support layer and would not penetrate the sublayer and 'smudge' the skin layer. For the PDA/ $\mathrm{Cu}^{2+}$ coated membrane, the colour of the support layer changed to black with a homogenous coating layer because of $\mathrm{Cu}^{2+}$ enhanced DA polymerization $\left(\mathrm{Cu}^{2+}\right.$ probably acting as an oxidant and metal chelate) [25].

(A)

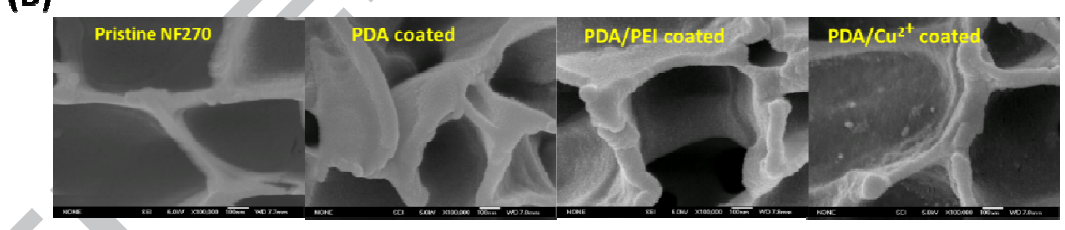

Fig. 2 Surface images of the biocatalytic membranes (A) and cross-sectional SEM morphologies of sublayer for the pristine and biocatalytic membranes (B).

Fig. 2B shows the cross-sectional SEM images of the sublayer for pristine membrane and different biocatalytic membranes. The obvious thickness increase after coating demonstrates that the coating layers are successfully formed on the polysulfone sublayer. However, there was no significant difference in coating thickness for these three coating strategies, indicating that the addition of PEI or $\mathrm{Cu}^{2+}$ into DA solution improved the density and uniformity of the coating layers rather than their thickness. Besides, as shown in Fig. 2B, several visible aggregates are found on the 
sublayer of the biocatalytic membrane coated by $\mathrm{PDA} / \mathrm{Cu}^{2+}$; by contrast, no visible aggregates could be observed on the other two membranes. This could be caused by the fact that since $\mathrm{Cu}^{2+}$ accelerated the polymerization rate of DA, some PDA aggregates formed in a short time would deposit in/on membrane, while the incorporation of PEI into PDA destructed the non-covalent interactions among PDA aggregates, increasing the uniformity and density of the coating layer.
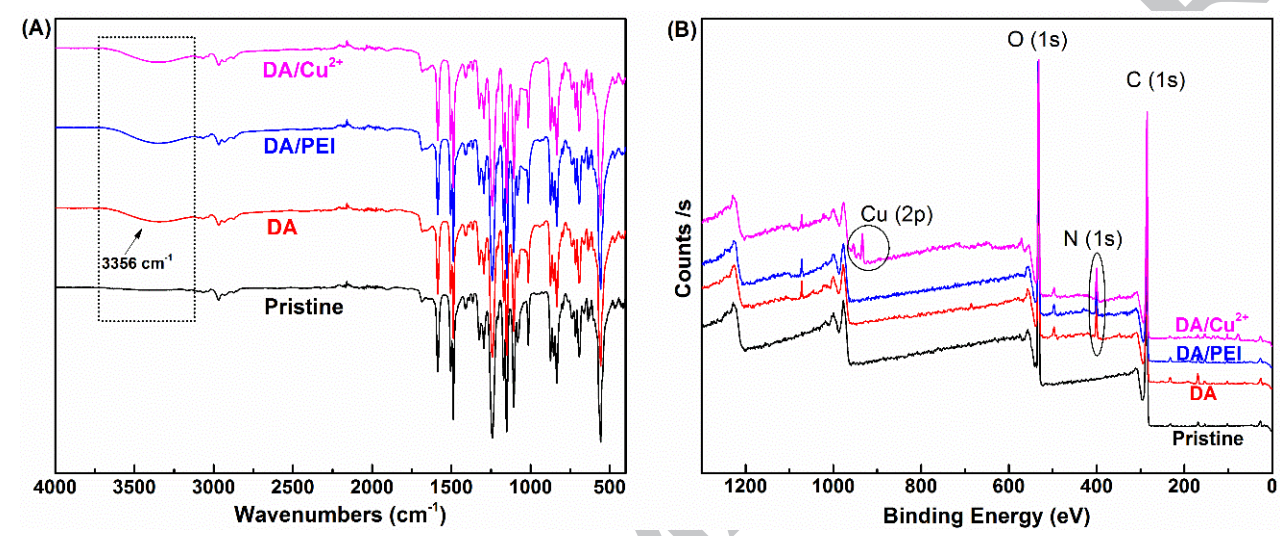

Fig. 3 FT-IR spectra (A) and XPS spectra (B) of the support of pristine membrane and PDA, PDA/PEI, $\mathrm{PDA} / \mathrm{Cu}^{2+}$ coated biocatalytic membranes.

FT-IR was used to analyse the chemical structure of the biocatalytic membrane surface (Fig. 3A). For all the biocatalytic membranes, a broad band centered at $3356 \mathrm{~cm}^{-1}$ was attributed to $\mathrm{N}-\mathrm{H}$ and $\mathrm{O}-\mathrm{H}$ stretching vibrations in the protein, implying the existence of laccase in/on the biocatalytic membranes [18]. Moreover, XPS was employed to determine the surface elemental compositions of different membranes (Fig. 3B). The main peaks of the pristine membrane were only C $1 \mathrm{~s}$ and $\mathrm{O} 1 \mathrm{~s}$, and the peak of $\mathrm{N} 1 \mathrm{~s}$ appeared for the biocatalytic membranes with different DA coating strategies, indicating successful PDA and PEI deposition. The surface N/O ratio for the membrane with PDA/PEI coating was larger than that with single PDA coating, 0.28 vs. 0.22 (Table 1), meaning that the PEI molecules were mixed into the coating layer since no oxygen element was present in PEI. For the PDA/ $\mathrm{Cu}^{2+}$ coated membrane, the binding energy peaks at $954.1 \mathrm{eV}$ and $933.5 \mathrm{eV}$ attributed to $\mathrm{Cu} 2 \mathrm{p}_{1 / 2}$ and $\mathrm{Cu} 2 \mathrm{p}_{3 / 2}$ orbitals respectively were observed, confirming the presence of 
copper on the membrane [27]. It is worth mentioning that for the PDA/PEI coated membrane, the binding energy peak at $933.7 \mathrm{eV}$ owing to $\mathrm{Cu}^{+}$or $\mathrm{Cu}^{0}$ was also detected (approximately $0.1 \%$ ), which was attributed to the immobilized laccase. It is well known that laccase is a multicopper oxidase containing three different copper atoms, and the PDA/PEI coated biocatalytic membrane had the highest laccase loading (70\%). For the single PDA coated biocatalytic membranes, such a peak was not observed because of its lower laccase loading (below the XPS detection limit). Furthermore, EDX was used to examine the distribution of copper ions on the PDA/Cu ${ }^{2+}$ coated biocatalytic membrane, showing that copper ions were distributed evenly on membrane surface (Fig. S1†).

Table 1 Elemental composition of pristine and three biocatalytic membranes.

\begin{tabular}{lllll}
\hline Element (\%) & Pristine & PDA & PDA/PEI & PDA/Cu ${ }^{2+}$ \\
\hline $\mathrm{C}$ & 72.70 & 67.48 & 68.73 & 68.39 \\
$\mathrm{~N}$ & 0.33 & 5.89 & 6.77 & 5.74 \\
$\mathrm{O}$ & 26.97 & 26.63 & 24.40 & 24.87 \\
$\mathrm{Cu}$ & - & - & 0.1 & 1 \\
\hline
\end{tabular}

\subsubsection{Enzyme loading, activity and permeability of biocatalytic membranes}

The enzyme loading, activity, and permeability variations at different enzyme immobilization stages as well as the water contact angle of the membrane support layer were measured. It can be seen in Fig. 4A that the enzyme loading in these membranes was in this order: PDA/PEI coated membrane $>\mathrm{PDA} / \mathrm{Cu}^{2+}$ coated membrane $>$ single PDA coated membrane, and such a difference was mainly caused by the different enzyme losses during the 'soaking and washing' stages. As aforementioned, the addition of PEI and $\mathrm{Cu}^{2+}$ into the DA solution can enhance the density and homogeneity of the coating layer, reducing the enzyme loss during the 'soaking and washing' stages. Especially for the DA/PEI co-deposition, this kind of coating layer could even be used for NF membrane fabrication after cross-linking [24], implying that the PDA/PEI layer was dense enough 
to 'seal' the enzyme in the membrane. Besides the higher enzyme loading, the PDA/PEI and PDA/ $\mathrm{Cu}^{2+}$ coatings also showed better anti-bacterial properties compared with the single PDA coating because PEI molecules and copper ions carried antibacterial ability [27, 32]. As seen in Fig. S2 $\uparrow$, after storage for 15 days, several bacterial colonies showed up on membrane surface with single PDA coating, while no visible bacterial colony was observed on the membrane with co-depositions. Moreover, it was reported that compared with the PDA layer, the PDA/PEI layer showed better stability under strongly alkaline conditions because of the covalent bonding between PDA and PEI [31], and the PDA/ $\mathrm{Cu}^{2+}$ layer was more stable at acidic pH [25-27]. All of these properties for the biocatalytic membranes with co-deposition can improve their stability in a long-term operation.
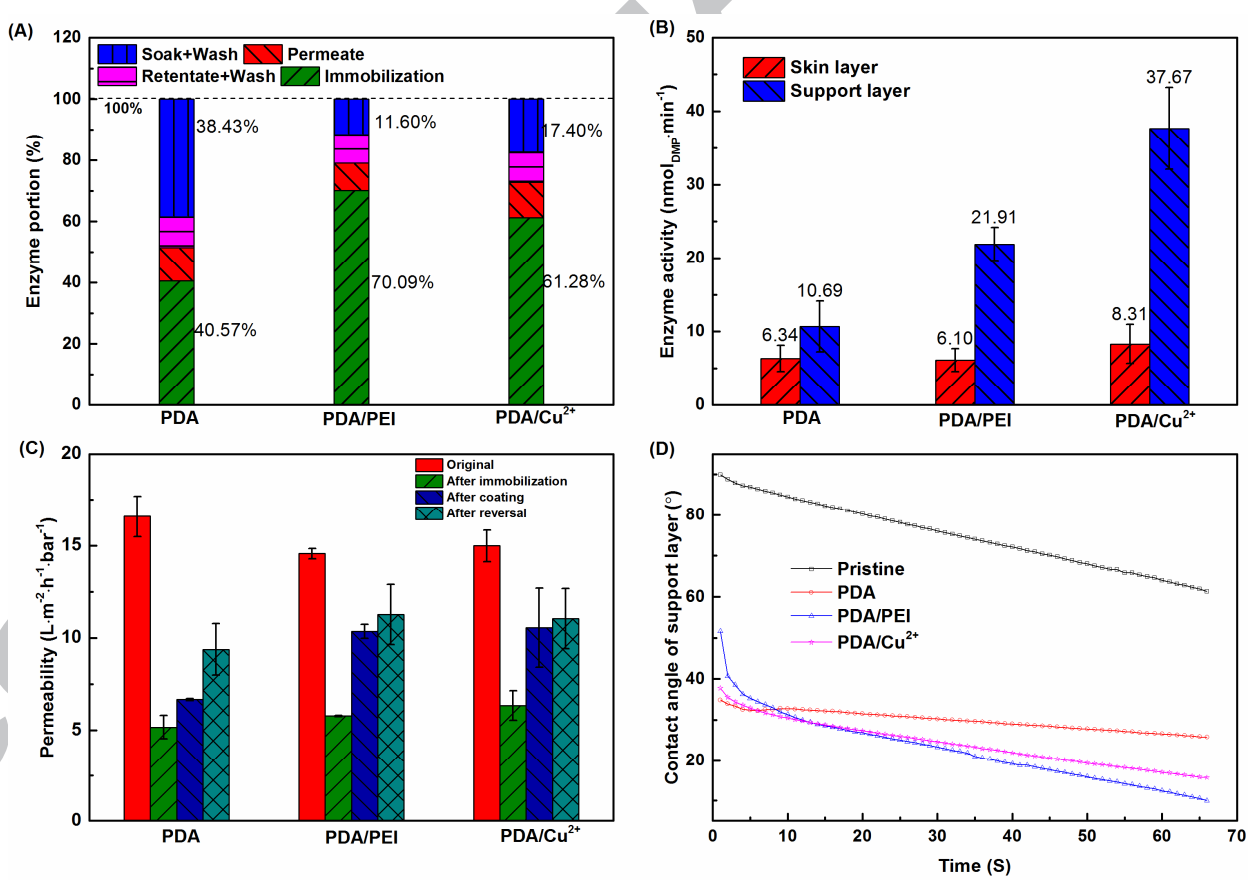

Fig. 4 Enzyme immobilization efficiency and enzyme losses at different immobilization stages when laccase was immobilized at $\mathrm{pH}$ 5.0, 4 bar, agitation speed of $100 \mathrm{rpm}$ followed by different coating protocols for $1 \mathrm{~h}$ at pH 8.5 (A), activity of skin and support layers (B), membrane permeability variations at different enzyme immobilization stages (C), and contact angle of different biocatalytic membranes' support layers (D). The error bars represent the standard deviation of at least three measurements. 
As aforementioned, the biocatalytic membranes prepared by 'reverse filtration' of laccase and subsequently dopamine-based coating could be used to construct 'bifacial EMR'. To verify this hypothesis, enzyme activity on both sides of the biocatalytic membranes was examined. As shown in Fig. 4B, both membrane skin layer and support/coating layer are enzymatically active towards DMP (although the activity of the skin layer is lower than that of the support layer due to the larger mass transfer resistance of the dense skin layer), demonstrating the validity of 'bifacial EMR' (its working mechanism is illustrated in Fig. 5). Furthermore, the activity of the support layer was greatly increased for the biocatalytic membranes with co-depositions, and the increase in enzyme loading was one of the possible reasons, but this could not explain why the PDA/Cu${ }^{2+}$ coated membrane had higher activity than the PDA/PEI coated one. Although PEI as a polyelectrolyte might enhance the electron transfer between laccase, oxygen and substrate, the electrostatic attraction between PEI and laccase possibly inhibited the enzyme activity [33]. Moreover, the dense PDA/PEI layer resulting in a higher diffusional resistance, leading to less DMP molecules passing through this coating layer to reach laccase, while the PDA/ $\mathrm{Cu}^{2+}$ coating layer was looser than the PDA/PEI layer (the latter had lowest enzyme loss). Most importantly, the extra deposited copper (1\%) could facilitate the electron transfer between laccase and substrate. It is well known that the catalysis of laccase starts with the donation of an electron to the substrate by one copper atom followed by the internal electron transfer from the reduced copper to the other two copper atoms [34], therefore the addition of copper ions in the coating layer might increase enzyme activity. The significantly improved activity of PDA/ $\mathrm{Cu}^{2+}$ coated membrane here verifies this hypothesis, which is also consistent with the previous report [28]. 


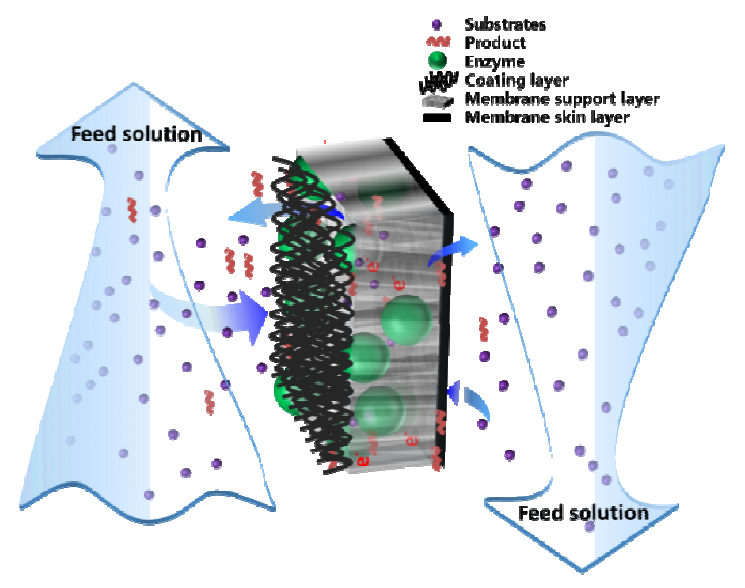

Fig. 5 Schematic illustration of working mechanism of the bifacial EMR.

Biocatalytic membranes with high enzyme loading but low permeability loss would be preferred. As shown in Fig. 4C, no matter which coating protocols was used, the membrane permeability declined dramatically after 'reverse filtration' due to membrane fouling formation (i.e. pore blocking or enzyme aggregate deposition) [18], and after coating, the permeability recovered to some extent owing to the high hydrophilicity of the coating layers. This was verified by the contact angle data shown in Fig. 4D, where the contact angle of the support layer significantly decreased after mussel-inspired coating. Although these coating layers would inevitably increase the membrane resistance, their positive effect on membrane hydrophilicity was dominant, thus increasing the membrane permeability. It is worth mentioning that the contact angle decreased with time for the membrane support coated with PDA/PEI or PDA/Cu ${ }^{2+}$, becoming much lower than that of the single PDA coated membrane, which was responsible for the higher membrane permeability after coating for the membrane with co-depositions. Moreover, the membrane permeability increased a little after membrane reversal because of the enzyme loss, especially for the membrane with single PDA coating.

\subsubsection{Stability of immobilized enzyme}




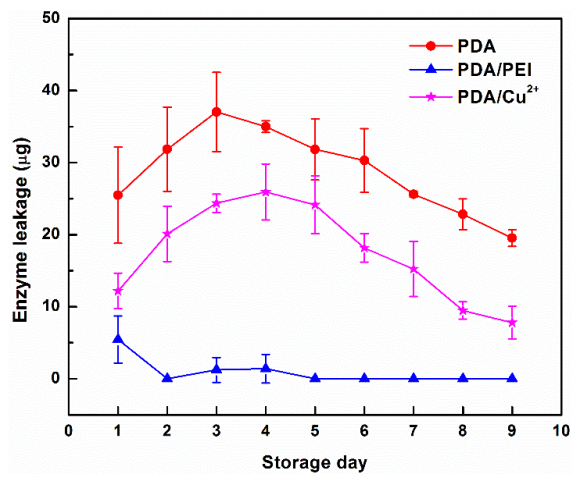

Fig. 6 Enzyme leakage of three biocatalytic membranes in neutral buffer during storage of 9 days. The error bars represent the standard deviation of at least three measurements.

The enzyme was mainly immobilized via entrapment, hydrophobic adsorption, sealing, and covalent bonding using this strategy (Fig. S3 $\dagger$ ), and among these interaction manners, physical interactions were dominant. Since these physical interactions are relative weak, enzyme would diffuse or leach from the membrane support easily $[17,18]$. Fig. 6 shows the enzyme leakage of three biocatalytic membranes during storage. The free enzyme amount in the 'storage buffer' first increases and then decreases for the membranes coated by single PDA and PDA/ $\mathrm{Cu}^{2+}$, and this observation is in accordance with our previous study [18]. The enzyme 'docked' in membrane would diffuse or 'leach' from the membrane support during storage, but some of the soluble enzyme could be readsorbed or covalently bound to the PDA layer with time (though this phenomenon would be avoided during real application under flow-through mode). Compared with the single PDA coated membrane, the PDA/ $\mathrm{Cu}^{2+}$ coated membrane showed lower enzyme leakage, while for the membrane coated with PDA/PEI, the enzyme leakage during storage was almost zero except a little laccase was washed away during the permeability determination in the first day. Although both co-deposition methods promoted DA polymerization, the stability of immobilized enzyme varied a lot. This was mainly caused by different density and homogeneity of these coating layers. The incorporation of PEI into PDA formed a much more compact PDA/PEI layer which could even be 
used to fabricate NF membrane; while some PDA aggregates formed at the presence of copper (in other words, PDA/Cu ${ }^{2+}$ layer was looser compared with PDA/PEI layer) (Fig. 2B). Besides, electrostatic attraction among negatively charged laccase and positively charged PEI also prevented enzyme leakage. In addition to enzyme leakage, natural enzyme inactivation was another reason for the stability loss of biocatalytic membranes, and it was found that enzyme inactivation played a more significant role in stability loss, especially with the extended storage time (Fig. S4 $\uparrow)$. As enzyme inactivation is inevitable, thus alleviating enzyme leakage is particularly important.

In summary, the biocatalytic membranes prepared by $\mathrm{DA} / \mathrm{PEI}$ and $\mathrm{DA} / \mathrm{Cu}^{2+}$ co-depositions outperformed the membrane with single PDA coating in terms of enzyme loading, activity, permeability as well as the stability of immobilized enzyme, being beneficial for their application.

\subsection{BPA removal in bifacial EMRs}

\subsubsection{Contribution of each side of the biocatalytic membrane to BPA removal}
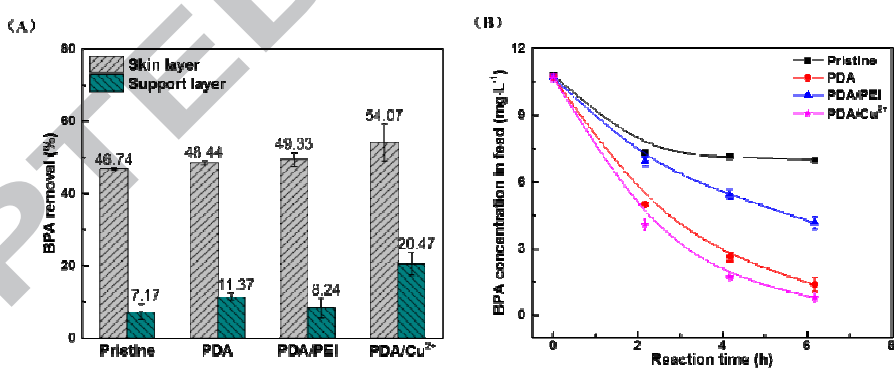

(c)

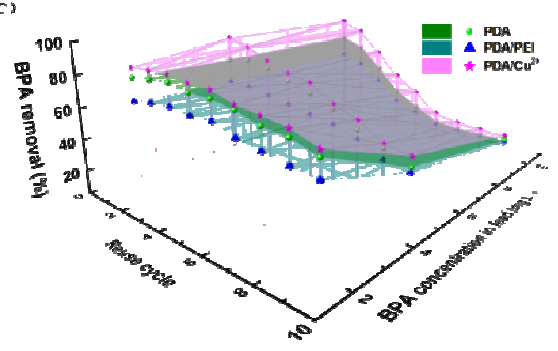

Fig. 7 BPA removal of skin/support layer by pristine and biocatalytic membranes when $10 \mathrm{~mL}$ BPA (5 $\mathrm{mg} \cdot \mathrm{L}^{-1}$ ) was treated with agitation speed of $100 \mathrm{rpm}$ for $1 \mathrm{~h}(\mathrm{~A})$, residual BPA concentration in feed when 20 $\mathrm{mL}$ BPA $\left(10 \mathrm{mg} \cdot \mathrm{L}^{-1}\right)$ was treated by the whole bifacial EMRs in contact mode (B), BPA removal efficiencies by the whole bifacial EMRs for 9 reuse cycles when $20 \mathrm{~mL}$ of BPA $\left(2,5,10 \mathrm{mg} \cdot \mathrm{L}^{-1}\right)$ was treated in contact mode $(C)$. The error bars represent the standard deviation of at least three measurements. 
As stated before, both sides of the biocatalytic membranes were enzymatically active, which were supposed to be used for BPA removal in the bifacial EMRs. As shown in Fig. 7A, for the pristine membrane, it can adsorb $46.74 \%$ and $7.17 \%$ of the BPA by the skin and support layers respectively. This was unexpected since the thickness of support layer (hundreds of micrometres) is much larger than that of skin layer (tens to hundreds of nanometres) (Fig. S5 $\dagger$ ). As $\pi-\pi$ stacking is the main mechanism of adsorption between BPA and polyamide skin layer while it is hydrophobic interaction for the adsorption between BPA and polypropylene support, it is speculated that $\pi-\pi$ stacking effect is much stronger for BPA adsorption. Besides, the apparent adsorption of skin layer may include that of sublayer because the sublayer is much closer to the skin layer. While for the biocatalytic membranes, they showed higher BPA removal for both sides compared with the pristine membrane, which was attributed to their catalytic ability by the enzyme rather than the adsorption by coating layers. Previous studies showed that although the mass of membrane increased due to coating, the adsorption did not increase accordingly because of the high hydrophilicity of the coating layer and supressed hydrophobic interaction [18, 35]. For PDA/PEI coated membrane, though it showed double enzyme activity compared with the single PDA coated membrane, the BPA removal by the support layer was not improved accordingly, even lower than that of the membrane with single PDA coating. This would appear to be due to the larger diffusional resistance for BPA $\left(228.29 \mathrm{~g} \cdot \mathrm{mol}^{-1}\right)$ than DMP $\left(154.16 \mathrm{~g} \cdot \mathrm{mol}^{-1}\right)$ by the PDA/PEI layer, which was much denser than the single PDA layer. Moreover, due to the $\mathrm{Cu}$-enhanced electron transfer and relatively low diffusional resistance of substrate/ product in the membrane, the PDA/ $\mathrm{Cu}^{2+}$ coated membrane had highest BPA removal for both sides, which was consistent with the enzyme activity results shown in 
Fig. 4B. Besides, it was also worth mentioning that these coating layers themselves could not catalyze BPA oxidation (Fig. S6 $\dagger$ ), and the synergist effect only existed in the presence of laccase.

\subsubsection{BPA removal in bifacial EMRs under contact mode}

To demonstrate the advantages of biocatalytic membranes prepared by mussel-inspired co-deposition in BPA removal, $20 \mathrm{~mL}$ of BPA solution was used to test the BPA removal by different membranes for a short-term operation, where the pristine membrane only adsorbed BPA, while the different biocatalytic membranes could simultaneously adsorb and oxidize BPA. By such comparison we could know the benefits of the biocatalytic membranes. Fig. 7B shows the BPA concentration variation in different EMRs for $6 \mathrm{~h}$ when BPA was treated in contact mode. For the pristine membrane, BPA concentration first declined subsequently remained constant for the last $3 \mathrm{~h}$ due to 'adsorption saturation'. In contrast, for the biocatalytic membranes, the BPA concentration fell with time, indicating that the 'adsorption saturation' of BPA was broken by the enzymatic oxidation. As similar to the results shown in Fig. 7A, the biocatalytic membrane coated with $\mathrm{PDA} / \mathrm{Cu}^{2+}$ showed the fastest BPA concentration decline, followed by the membrane coated with single PDA. To further clarify the BPA removal mechanism, the mathematic models were employed to analyze the reaction kinetics by fitting the data in Fig. 7B (detailed information about mathematic modelling was presented in Supplementary Data S7) [36]. The fitted kinetic parameters displayed in Table 2 clearly demonstrated that BPA removal rate was accelerated by co-deposition of $\mathrm{DA} / \mathrm{Cu}^{2+}$ due to copper-enhanced electron transfer between laccase and micro-pollutant. As shown in Table 2, the reaction rate constant $k$ for the biocatalytic membranes coated with single PDA and $\mathrm{PDA} / \mathrm{Cu}^{2+}$ was $0.0055 \mathrm{~min}^{-1}$ and $0.0070 \mathrm{~min}^{-1}$ respectively, and correspondingly, the half-life $\left(\mathrm{t}_{1 / 2}\right)$ of BPA for the two biocatalytic membranes was shortened dramatically. However, the reaction rate 
constant $k$ of PDA/PEI coated membrane was much smaller than that of the other two membranes, and BPA half-life was also much longer. In addition to the larger diffusional resistance, the adverse effect of electrostatic interaction between laccase and PEI on laccase activity might be responsible for this.

Comparing with the results in other reports (displayed in Table S2), the BPA removal efficiency of the PDA/Cu ${ }^{2+}$ coated membrane under incubation mode was competitive to others. Moreover, it should be noted that the initial laccase activity used in other works was at least ten times higher than the one used in the current work, and our biocatalytic membrane preparation method is also simpler and cheaper.

Table 2 BPA removal reaction rate constant $(k)$ and half-life $\left(\mathrm{t}_{1 / 2}\right)$ by three biocatalytic membranes

\begin{tabular}{cccc}
\hline Kinetic parameter & $\boldsymbol{k}$ & $\mathbf{t}_{\mathbf{1} / 2}(\mathbf{m i n})$ & $\mathbf{R}^{2}$ \\
\hline Single PDA coating $^{\mathrm{a}}$ & $0.0055 \mathrm{~min}^{-1}$ & 126.0 & 0.9995 \\
PDA/PEI coating $^{\mathrm{a}}$ & $0.0025 \mathrm{~min}^{-1}$ & 277.3 & 0.9855 \\
PDA/Cu$^{2+}$ coating $^{\mathrm{a}}$ & $0.0070 \mathrm{~min}^{-1}$ & 99.02 & 0.9989 \\
PDA/PEI coating $^{\mathrm{b}}$ & $0.0004 \mathrm{~L} \cdot \mathrm{mg}^{-1} \cdot \mathrm{min}^{-1}$ & 233.6 & 0.9961 \\
\hline
\end{tabular}

${ }^{\mathrm{a}}$ Reaction kinetics fitted by first-order reaction principle.

${ }^{\mathrm{b}}$ Reaction kinetics fitted by second-order reaction principle.

On the other hand, it should be noted that the BPA removal efficiency slowed down with time (Fig. 7B), possibly due to the lower substrate concentration, product inhibition and membrane fouling. In order to clarify the mechanisms behind the removal efficiency decline in the EMRs, the biocatalytic membranes were reused for BPA removal in batches, where it was found that the BPA removal efficiency decreased with increasing reuse cycle (Fig. S8 $\dagger$ ), which was also reported in previous studies $[18,37]$. Since the fresh feed is added each time, the substrate concentration decrease is not the cause. In addition to the natural enzyme deactivation and enzyme leakage, the 
deposition of the BPA oxidation products in the membrane might be mainly responsible for the efficiency reduction of BPA removal in the EMRs. It is well known that with laccase, BPA is oxidized to some reactive intermediates first, then to quinone and finally polymerized [13]. We speculated that BPA oxidation products with a larger molecular weight would accumulate in/on membrane due to entrapment and adsorption, and this 'fouling layer' could not only cover the active site of laccase, but also produce diffusional resistance for the substrate, decreasing BPA removal. This hypothesis could be partly verified by the results of $\mathrm{pH}$ effect on BPA removal and residual laccase activity (Fig. S9†). Though the laccase from Trametes versicolor was more active in acidic $\mathrm{pH}$ for the degradation of phenolic compounds [38], BPA removal in this case was highest at neutral $\mathrm{pH}$. Since the polyamide membrane became more hydrophilic and charged at higher $\mathrm{pH}$, less adsorption of oxidation products in/on the membrane resulted in higher BPA removal and residual activity.

To further verify this hypothesis, the biocatalytic membranes were reused for 9 cycles to treat BPA solutions with different concentrations in the bifacial EMRs under contact mode. As shown in Fig. 7C, higher BPA concentration in the EMRs results in faster decline in BPA removal efficiency. When the initial BPA concentration increased from 2 to $10 \mathrm{mg} \cdot \mathrm{L}^{-1}$, the $\mathrm{BPA}$ removal decline rate raised from $14-18 \%$ to $72-76 \%$ after 9 reuse cycles (Table S3). Higher BPA concentration could increase the reaction rate, leading to more product formation and severer membrane fouling, which subsequently induced more serious BPA removal decline. On the other hand, when compared to the BPA removal decline for different biocatalytic membranes, the membrane with higher BPA removal efficiency (i.e. generating more BPA oxidation products) showed greater BPA removal decline. Thus, it might be concluded that the products accumulation in/on the membrane caused the BPA 
removal decline with increasing reuse cycle. This could also be confirmed by the membrane contact angle increase after BPA removal (Table S4) because the hydrophobic BPA oxidation products adsorbed on the membrane surface would decrease the membrane hydrophilicity. Besides, XPS analysis of the membrane surface composition could also prove the accumulation of catalytic products. For example, the $\mathrm{C} / \mathrm{O}$ ratio of the PDA/PEI coated membrane increased from 2.82 to 3.32 after BPA treatment for 9 cycles $\left(20 \mathrm{~mL}, 5 \mathrm{mg} \cdot \mathrm{L}^{-1}\right.$, contact mode, room temperature, agitation speed of $100 \mathrm{rpm}, 6 \mathrm{~h})$. Likewise, the $\mathrm{C} / \mathrm{O}$ ratio of $\mathrm{BPA}\left(\mathrm{C}_{15} \mathrm{H}_{16} \mathrm{O}_{2}\right)$ was 7.5 , and we reasoned that the BPA oxidation products on the membrane increased the $\mathrm{C} / \mathrm{O}$ ratio of the biocatalytic membrane. On the other hand, as seen from Fig. 7C, the difference of BPA removal efficiency between the PDA coated membrane and $\mathrm{PDA} / \mathrm{Cu}^{2+}$ coated membrane is not significant when the substrate concentration is low (i.e. 2 and $5 \mathrm{mg} \cdot \mathrm{L}^{-1}$ ). When BPA feed concentration was $10 \mathrm{mg} \cdot \mathrm{L}^{-1}$, the PDA/ $\mathrm{Cu}^{2+}$ coated membrane outperformed the single PDA coated membrane (BPA removal efficiency in the first cycle: $92 \%$ vs $77 \%$ ). This phenomenon suggested that the potential of PDA/ $\mathrm{Cu}^{2+}$ coated membrane could be fully exploited at higher BPA concentration. However, faster reaction rate of $\mathrm{PDA} / \mathrm{Cu}^{2+}$ coated membrane leaded to more product formation and severer membrane fouling, producing adverse impact on overall BPA removal performance in return.

Above all, we conclude that the accumulation of enzymatic products in/on membrane was detrimental to the stability of the bifacial EMRs. We hypothesized that the in-situ product removal from the membrane during the reaction could break this trade-off, and thus the bifacial EMRs were operated under flow-through mode in the following study, where the pressure-induced convective mass transfer might wash the products away during the reaction.

\subsubsection{BPA removal in bifacial EMRs under flow-through mode}




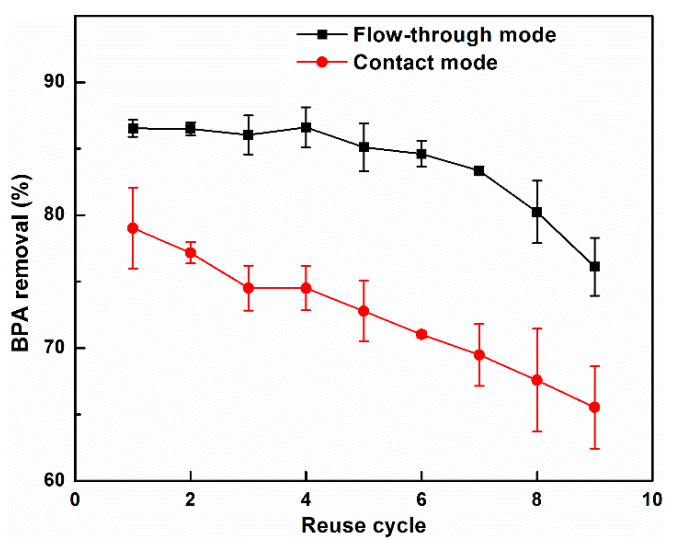

Fig. 8 BPA removal in bifacial EMRs in contact and flow-through modes $\left(\mathrm{PDA} / \mathrm{Cu}^{2+}\right.$ coated, BPA treatment conditions: $20 \mathrm{~mL}, 2 \mathrm{mg} \cdot \mathrm{L}^{-1}$, room temperature, agitation speed of $100 \mathrm{rpm}, 6 \mathrm{~h}$ ). The error bars represent the standard deviation of at least three measurements.

The PDA/ $\mathrm{Cu}^{2+}$ coated membrane with the highest BPA removal efficiency was selected to evaluate the bifacial EMR's performance in flow-through mode since it has been proved that the copper release from such membrane was hundred times lower than the limit value in drinking water [27]. As seen in Fig. 8, the EMR operated in flow-through mode shows much higher and more stable BPA removal than that in contact mode. This could be explained as follows. For the EMR operated in contact mode, the immobilized enzyme in the membrane was not fully exploited due to mass transfer limitation in the membrane, making it difficult for BPA to reach all the enzyme. Likewise, the products would also be diffusional limited. For the EMR operated in flow-through mode, the pressure-induced convective transport across the membrane could overcome the diffusion barrier, and the contact of BPA and enzyme in the membrane as well as the removal of the product from the membrane would therefore be enhanced, leading to a high catalytic efficiency and a low product accumulation. This explanation was verified by the variations of membrane hydrophilicity before and after BPA treatment. The contact angle of the membrane support layer increased to $68.71 \pm 4.59^{\circ}$ and $53.07 \pm 3.88^{\circ}$ for the EMRs in contact and flow-through modes after 9 reuse cycles (the contact angle of their skin layer increased to $71.00 \pm 6.85^{\circ}$ and $57.90 \pm 5.57^{\circ}$ ) respectively, 
implying the accumulation of hydrophobic products on membrane was less serious for the flow-through EMR.

\subsection{Mechanism discussion}

Since the diffusional resistance to micro-pollutants/ products in the membrane was detrimental to micro-pollutants removal efficiency and stability of the bifacial EMRs, we fabricated a single-sided EMR where the enzyme was immobilized on membrane skin layer (more details could be found in Supplementary data S11). Although the enzyme loading on the skin layer was extremely low (around $3 \mu \mathrm{g}$ ), the single-sided EMR in contact mode showed relatively high BPA removal efficiency $(30-45 \%)$ in the first cycle because BPA could readily react with laccase on membrane surface (Fig. S10 $†$ A). However, the BPA removal efficiency dropped dramatically with increased reuse cycles, and after 5 cycles, it virtually declined to zero, implying product accumulation on membrane still occurred (covered enzyme active sites) due to the fast enzymatic polymerization of BPA (high BPA concentration near the immobilized enzyme) and severe product adsorption. The permeability decline of the biocatalytic membrane (7.87\%) after reuse further confirmed this hypothesis. Therefore, the trade-off between BPA removal efficiency and reuse stability still exists in the single-sided EMR when contact mode was applied. When this single-sided EMR was operated in flow-through mode, due to the enhanced convective transport of BPA to enzyme, the reuse stability was better than that in contact mode. For the bifacial EMR with the PDA/PEI coated membrane, although its BPA removal efficiency was always higher than that of the single-sided EMR, the reuse stability was also poor in all operation modes (Fig. S10 $† \mathbf{B})$, mainly because of the entrapment of the BPA oxidation products by the denser PDA/PEI coating layer. 
In order to construct a highly efficient and stable EMR for BPA removal, it is necessary to control the enzymatic reaction speed, avoiding the formation of large polymerized products, and at the same time, the mass transfer of BPA/products should be manipulated, providing enough time for reaction while removing the products immediately. Therefore, the flow-through EMR was preferred because the reaction time could be controlled by adjusting the permeate flux and the products would be washed away by the convective mass transfer. For the biocatalytic membrane, the immobilized enzyme should be in/on the porous layer for the transmission of polymerized enzymatic products. Furthermore, the catalytic activity would like to be relatively high to shorten the reaction time and enhance micro-pollutants removal. Based on these observation, the bifacial EMR with PDA/ $\mathrm{Cu}^{2+}$ coated membrane operated in flow-through mode would be preferred.

\section{Conclusions}

In this work, we applied mussel-inspired co-deposition on NF membrane support to ameliorate enzyme loading, activity and stability of the biocatalytic membrane for BPA removal. Both sides of the biocatalytic membranes were enzymatically active, which were utilized to construct a bifacial EMR for efficient micro-pollutants removal. Compared with the single DA deposition, DA/PEI co-deposition improved enzyme loading most significantly due to the dense coating, while the bifacial EMR with PDA/ $\mathrm{Cu}^{2+}$ coated membrane displayed the highest activity and highest BPA removal because of the copper-enhanced electron transfer between laccase and micro-pollutant. It was also found that the product accumulation in/on membrane was a cause for BPA removal efficiency decline, which could be overcome by the pressure-induced convective mass transfer, as it not only promoted the contact possibility between micro-pollutants and enzyme, but also achieved 
in situ product removal. This work clearly confirmed the benefits of the DA/PEI and DA/Cu${ }^{2+}$ co-deposition for laccase immobilization, and demonstrated the potential to achieve a high and stable micro-pollutants removal performance by manipulating the enzyme loading, location and activity as well as micro-pollutants/products mass transfer of the biocatalytic membrane.

\section{Acknowledgements}

This work was supported by the National Science Foundation of China (No. 21506229), “100 Talents Program" and Youth Innovation Promotion Association (2017069) of Chinese Academy of Sciences.

\section{Appendix A. Supplementary data}

Supplementary data related to this article can be found at http://dx.doi.org.

\section{References}

[1] L.N. Nguyen, F.I. Hai, A. Dosseto, C. Richardson, W.E. Price, L.D. Nghiem, Continuous adsorption and biotransformation of micropollutants by granular activated carbon-bound laccase in a packed-bed enzyme reactor, Bioresour. Technol. 210 (2016) 108-116.

[2] J. Hou, G. Dong, B. Luu, R.G. Sengpiel, Y. Ye, M. Wessling, V. Chen, Hybrid membrane with $\mathrm{TiO}_{2}$ based bio-catalytic nanoparticle suspension system for the degradation of bisphenol-A, Bioresour. Technol. 169 (2014) 475-483.

[3] R. Rosal, A. Rodríguez, J.A. Perdigón-Melón, A. Petre, E. García-Calvo, M.J. Gómez, A. Agüera, A.R. Fernández-Alba, Occurrence of emerging pollutants in urban wastewater and their removal through biological treatment followed by ozonation, Water Res. 44 (2010) 578-588.

[4] R. Xu, Y. Si, X. Wu, F. Li, B. Zhang, Triclosan removal by laccase immobilized on mesoporous nanofibers: Strong adsorption and efficient degradation, Chem. Eng. J. 255 (2014) 63-70.

[5] M.d. Cazes, M.-P. Belleville, M. Mougelb, H. Kellner, J. Sanchez-Marcano, Characterization of laccase-grafted ceramic membranes for pharmaceuticals degradation, J. Membr. Sci. 476 (2015) 384-393.

[6] E.N. de Freitas, G.A. Bubna, T. Brugnari, C.G. Kato, M. Nolli, T.G. Rauen, R.d.F. Peralta Muniz Moreira, R.A. Peralta, A. Bracht, C.G.M. de Souza, R.M. Peralta, Removal of bisphenol A by laccases from Pleurotus ostreatus and Pleurotus pulmonarius and evaluation of ecotoxicity of degradation products, Chem. Eng. J. 330 (2017) 1361-1369. 
[7] Y. Cui, X.-Y. Liu, T.-S. Chung, M. Weber, C. Staudt, C. Maletzko, Removal of organic micro-pollutants (phenol, aniline and nitrobenzene) via forward osmosis (FO) process: Evaluation of FO as an alternative method to reverse osmosis (RO), Water Res. 91 (2016) 104-114.

[8] M. Zambianchi, M. Durso, A. Liscio, E. Treossi, C. Bettini, M.L. Capobianco, A. Aluigi, A. Kovtun, G. Ruani, F. Corticelli, M. Brucale, V. Palermo, M.L. Navacchia, M. Melucci, Graphene oxide doped polysulfone membrane adsorbers for the removal of organic contaminants from water, Chem. Eng. J. 326 (2017) 130-140.

[9] L. Balest, G. Mascolo, C. Di Iaconi, A. Lopez, Removal of endocrine disrupter compounds from municipal wastewater by an innovative biological technology, Water Sci. Technol. 58 (2008) 953-956.

[10] G. Bertanza, R. Pedrazzani, M. Dal Grande, M. Papa, V. Zambarda, C. Montani, N. Steimberg, G. Mazzoleni, D. Di Lorenzo, Effect of biological and chemical oxidation on the removal of estrogenic compounds (NP and BPA) from wastewater: an integrated assessment procedure, Water Res. 45 (2011) 2473-2484.

[11] T. Basile, A. Petrella, M. Petrella, G. Boghetich, V. Petruzzelli, S. Colasuonno, D. Petruzzelli, Review of endocrine-disrupting-compound removal technologies in water and wastewater treatment plants: an EU perspective, Ind. Eng. Chem. Res. 50 (2011) 8389-8401.

[12] Y. Jeong, K. Cho, E.E. Kwon, Y.F. Tsang, J. Rinklebe, C. Park, Evaluating the feasibility of pyrophyllite-based ceramic membranes for treating domestic wastewater in anaerobic ceramic membrane bioreactors, Chem. Eng. J. 328 (2017) 567-573.

[13] J. Hou, G. Dong, Y. Ye, V. Chen, Enzymatic degradation of bisphenol-A with immobilized laccase on $\mathrm{TiO}_{2}$ sol-gel coated PVDF membrane, J. Membr. Sci. 469 (2014) 19-30.

[14] L. Lloret, G. Eibes, M.T. Moreira, G. Feijoo, J.M. Lema, Removal of estrogenic compounds from filtered secondary wastewater effluent in a continuous enzymatic membrane reactor. Identification of biotransformation products, Environ. Sci. Technol. 47 (2013) 4536-4543.

[15] S.R. Couto, J.L.T. Herrera, Industrial and biotechnological applications of laccases: a review, Biotechnol. Adv. 24 (2006) 500-513.

[16] L. Giorno, E. Drioli, G. Carvoli, A. Cassano, L. Donato, Study of an enzyme membrane reactor with immobilized fumarase for production of L-malic acid, Biotechnol. Bioeng. 72 (2001) 77-84.

[17] J. Luo, A.S. Meyer, R.V. Mateiu, D. Kalyani, M. Pinelo, Functionalization of a membrane sublayer using reverse filtration of enzymes and dopamine coating, ACS Appl. Mater.Interfaces 6 (2014) 22894-22904.

[18] X. Cao, J. Luo, J.M. Woodley, Y. Wan, Bioinspired multifunctional membrane for aquatic micropollutants removal, ACS Appl. Mater.Interfaces 8 (2016) 30511-30522.

[19] H. Lee, S.M. Dellatore, W.M. Miller, P.B. Messersmith, Mussel-inspired surface chemistry for multifunctional coatings, Science 318 (2007) 426-430.

[20] Z.-X. Wang, C.-H. Lau, N.-Q. Zhang, Y.-P. Bai, L. Shao, Mussel-inspired tailoring of membrane wettability for harsh water treatment, J. Mater. Chem. A 3 (2015) 2650-2657.

[21] G. Zeng, Z. Ye, Y. He, X. Yang, J. Ma, H. Shi, Z. Feng, Application of dopamine-modified halloysite nanotubes/PVDF blend membranes for direct dyes removal from wastewater, Chem. Eng. J. 323 (2017) 572-583.

[22] X. Fang, J. Li, X. Li, S. Pan, X. Zhang, X. Sun, J. Shen, W. Han, L. Wang, Internal pore decoration with polydopamine nanoparticle on polymeric ultrafiltration membrane for enhanced heavy metal removal, Chem. Eng. J. 314 (2017) 38-49.

[23] H.-C. Yang, M.-B. Wu, Y.-J. Li, Y.-F. Chen, L.-S. Wan, Z.-K. Xu, Effects of polyethyleneimine molecular weight and proportion on the membrane hydrophilization by codepositing with dopamine, J. Appl. Polym. Sci. 133 (2016) 43792.

[24] Y. Lv, H.-C. Yang, H.-Q. Liang, L.-S. Wan, Z.-K. Xu, Nanofiltration membranes via co-deposition of polydopamine/polyethylenimine followed by cross-linking, J. Membr. Sci. 476 (2015) 50-58. 
[25] C. Zhang, Y. Ou, W.-X. Lei, L.-S. Wan, J. Ji, Z.-K. Xu, $\mathrm{CuSO}_{4} / \mathrm{H}_{2} \mathrm{O}_{2}$-induced rapid deposition of polydopamine coatings with high uniformity and enhanced stability, Angew.Chem. 128 (2016) 3106-3109.

[26] V. Ball, J. Gracio, M. Vila, M.K. Singh, M.H. Metz-Boutigue, M. Michel, J. Bour, V. Toniazzo, D. Ruch, M.J. Buehler, Comparison of synthetic dopamine-eumelanin formed in the presence of oxygen and $\mathrm{Cu}^{2+}$ cations as oxidants, Langmuir 29 (2013) 12754-12761.

[27] Z. Liu, Y. Hu, C. Liu, Z. Zhou, Surface-independent one-pot chelation of copper ions onto filtration membranes to provide antibacterial properties, Chem. Commun. 52 (2016) 12245-12248.

[28] R. Xu, J. Cui, R. Tang, F. Li, B. Zhang, Removal of 2,4,6-trichlorophenol by laccase immobilized on nano-copper incorporated electrospun fibrous membrane-high efficiency, stability and reusability, Chem. Eng. J. 326 (2017) 647-655.

[29] M.E. Lynge, R.v.d. Westen, A. Postmab, B. Stadler, Polydopamine-a nature-inspired polymer coating for biomedical science, Nanoscale 3 (2011) 4916-4928.

[30] B. Sun, W. Hong, E.S. Thibau, H. Aziz, Z.H. Lu, Y. Li, Polyethylenimine (PEI) as an effective dopant to conveniently convert ambipolar and p-type polymers into unipolar n-type polymers, ACS Appl. Mater.Interfaces 7 (2015) 18662-18671.

[31] H.-C. Yang, K.-J. Liao, H. Huang, Q.-Y. Wu, L.-S. Wan, Z.-K. Xu, Mussel-inspired modification of a polymer membrane for ultra-high water permeability and oil-in-water emulsion separation, J. Mater. Chem. A 2 (2014) 10225-10230.

[32] I.M. Helander, H.L. Alakomi, K. LatvaKala, P. Koski, Polyethyleneimine is an effective permeabilizer of Gram-negative bacteria, Microbiology-(UK) 143 (1997) 3193-3199.

[33] J. Heller, A. Heller, Loss of activity or gain in stability of oxidases upon their immobilization in hydrated silica: significance of the electrostatic interactions of surface arginine residues at the entrances of the reaction channels, J. Am. Chem. Soc. 120 (1998) 4586-4590.

[34] M. Fernandez-Fernandez, M.A. Sanroman, D. Moldes, Recent developments and applications of immobilized laccase, Biotechnol. Adv. 31 (2013) 1808-1825.

[35] H. Guo, Y. Deng, Z. Yao, Z. Yang, J. Wang, C. Lin, T. Zhang, B. Zhu, C.Y. Tang, A highly selective surface coating for enhanced membrane rejection of endocrine disrupting compounds: Mechanistic insights and implications, Water Res. 121 (2017) 197-203.

[36] Y. Dai, J. Yao, Y. Song, S. Wang, Y. Yuan, Enhanced adsorption and degradation of phenolic pollutants in water by carbon nanotube modified laccase-carrying electrospun fibrous membranes, Environ. Sci.: Nano 3 (2016) 857-868.

[37] D. Spinelli, E. Fatarella, A. Di Michele, R. Pogni, Immobilization of fungal (Trametes versicolor) laccase onto Amberlite IR-120 H beads: optimization and characterization, Process Biochem. 48 (2013) 218-223.

[38] M.d. Cazes, M.P. Belleville, E. Petit, M. Llorca, S. Rodríguez-Mozaz, J. de Gunzburg, D. Barceló, J. Sanchez-Marcano, Design and optimization of an enzymatic membrane reactor for tetracycline degradation, Catal. Today 236 (2014) 146-152. 


\section{Highlights}

- Mussel-inspired co-deposition is applied to prepare biocatalytic membrane.

- PDA/PEI coating layer significantly prevents enzyme leakage.

- $\mathrm{PDA} / \mathrm{Cu}^{2+}$ coating layer improves immobilized laccase activity and BPA removal.

- Polymerized product accumulation in membrane results in the decline of BPA removal.

- Pressure-driven convection increases substrate accessibility and in-situ product removal. 


\section{Graphic abstract}

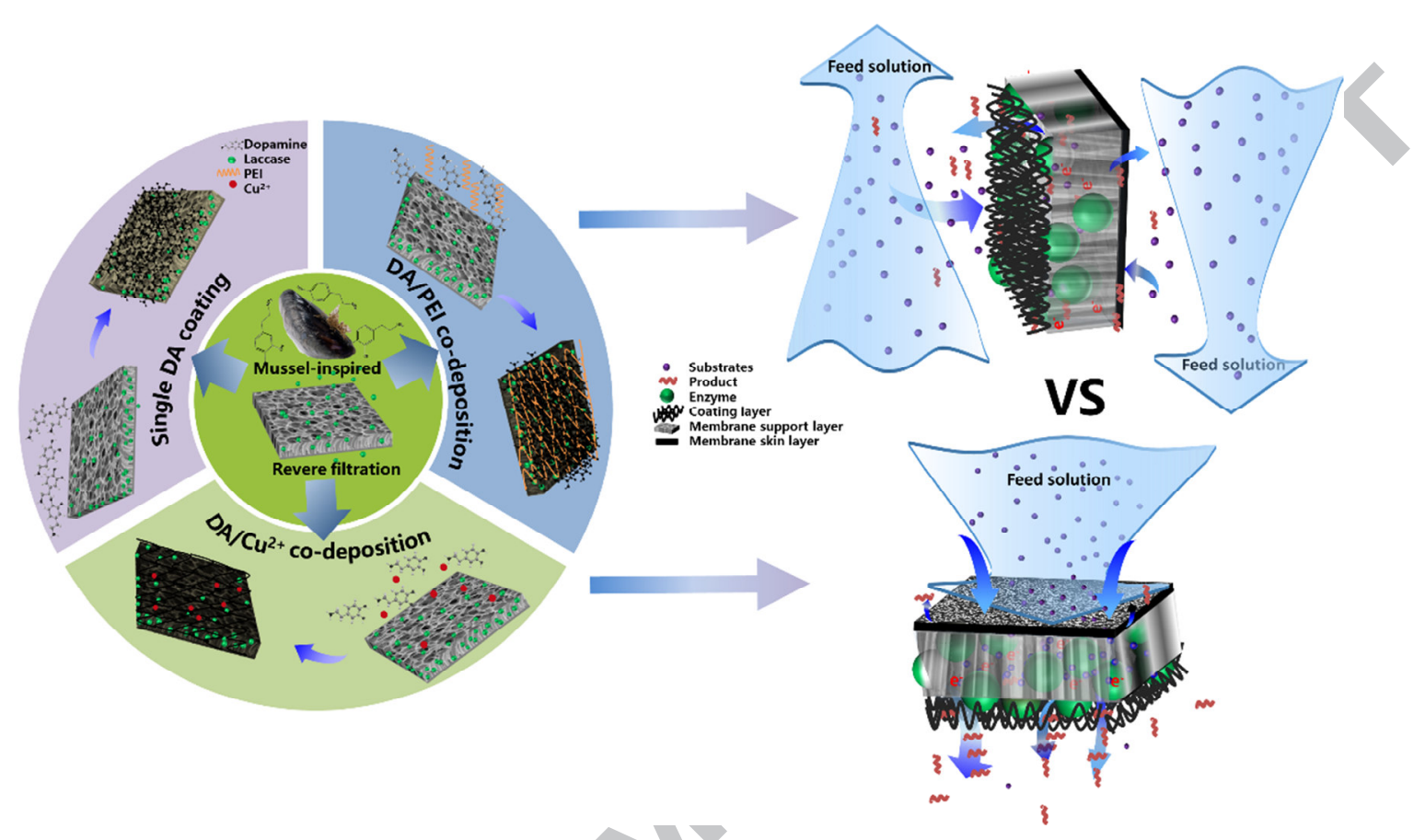

